\title{
Study on the structure and composition of aortic valve calcific deposits: Etiological aspects
}

\author{
Rafael. M. Prieto ${ }^{1,2}$, I. Gomila ${ }^{1}$, O. Söhnel ${ }^{3}$, A. Costa-Bauza ${ }^{1,2}$, O. Bonnin ${ }^{4}$, Felix Grases ${ }^{1,2}$ \\ ${ }^{1}$ Laboratory of Renal Lithiasis Research, University Institute of Health Sciences Research (IUNICS), University of Balearic Islands, \\ Palma of Mallorca, Spain; fgrases@uib.es \\ ${ }^{2}$ CIBER Fisiopatología Obesidad y Nutrición (CB06/03), Instituto de Salud Carlos III, Madrid, Spain; \\ ${ }^{3}$ University of J.E. Purkyne, Faculty of Environmental Studies, Usti n.L., Czech Republic; \\ ${ }^{4}$ University Hospital Son Dureta, Palma of Mallorca, Spain;
}

Received 5 November 2010; revised 19 November 2010; accepted 25 November 2010.

\begin{abstract}
The structures and chemical compositions of valve calcific deposits were investigated. The deposits was chosen arbitrarily and subjected to chemical analysis, observation with scanning microscope, semi-quantitative determination of $\mathrm{Ca}, \mathrm{Mg}, \mathrm{Na}, \mathrm{K}, \mathrm{P}$ and $\mathrm{C}$ elements by energy dispersive X-ray, X-ray diffraction and Fourier transform infra-red spectroscopy carried out. These deposits were found to have non-uniform internal structures composed of layers of a structureless aspidinic inorganic material, substantial amounts of voluminous organic material and in a few samples small spheres were also present. Two groups of deposits with distinctly different chemical compositions were identified: one group with a low Ca/P molar ratio (1.59) and the other group with a high (1.82) Ca/P molar ratio. The deposits belonging to the group with a low $\mathrm{Ca} / \mathrm{P}$ molar ratio contain higher concentration of magnesium and consist of increased amount of amorphous calcium phosphate. The deposits with a high $\mathrm{Ca} / \mathrm{P}$ molar ratio contain low concentration of magnesium and consist predominantly of carbonated hydroxyapatite. The inorganic material was identified as a poorly crystalline carbonate hydroxyapatite containing molecular water of the average formula $\mathrm{Ca}_{9.1} \mathrm{Mg}_{0.4}(\mathrm{Na}, \mathrm{K})\left(\mathrm{PO}_{4}\right)_{5.8}\left(\mathrm{CO}_{3}\right)_{0.3}(\mathrm{OH})_{2}$. The actual chemical composition of the apatitic solid phase varies not only from deposit to deposit but also within the same deposit. The non-uniform internal structure of the deposits, the occasional presence of spherical particles and the variable point composition of the individual deposits indicate that their formation did not proceed under more or less constant conditions.
\end{abstract}

Keywords: Mitochondrial Swelling; Cytochrome C Release; Calcium; Alloxan; Mitochondrial Permeability Transition

\section{INTRODUCTION}

The formation and composition of calcific deposits in living organisms have been intensively investigated with different methods in both in vitro and in vivo studies. This phenomenon is still not very well understood despite all effort devoted to its unravelling. The principle obstacle hindering conclusive elucidation of calcification stems from the impossibility of observing the commencement of formation of solid deposits in a living organism and their subsequent development. In the initial stages of a calcific deposit, moreover, formation of nanoparticles is undetectable under physiological conditions with contemporary methods and thus even in vitro studies cannot provide direct insight into the processes taking place during this crucial period of solid phase formation.

The fine structure, chemical composition and crystallinity of the deposits arising from the calcification of human natural and bioprosthetic heart valve have been investigated by using X-ray diffraction, Fourier transform infrared (hereafter FTIR) and Raman spectra, chemical and energy dispersive X-ray (hereafter EDX) analysis and high-resolution transmission electron microscopy [1-7]. In these studies, however, only the total compositions of the calcific deposits expressed as the molar ratio $\mathrm{Ca} / \mathrm{P}$ were determined.

The variation in the composition of calcific deposits between different individuals has previously been studied. However, whether and to what extent the composition of the calcific deposits in the same individual can vary is not known.

The object of this study was to determine the extent in variation in the structure and chemical composition of 
calcific deposits formed in explanted natural human aortic valves of the same and different individuals.

\section{MATERIALS AND METHODS}

\subsection{Sample Preparation}

Calcified natural heart valves surgically removed from 10 patients were kept in $10 \%$ aqueous solution of formaldehyde containing $7.65 \mathrm{~g}$ of $\mathrm{NaCl}, 0.724 \mathrm{~g}$ of $\mathrm{Na}_{2} \mathrm{HPO}_{4}$ and $0.21 \mathrm{~g}$ of $\mathrm{KH}_{2} \mathrm{PO}_{4}(\mathrm{pH} 7.2)$ in $1000 \mathrm{ml}$. From the numerous calcified objects formed within the valve tissue of each patient a well developed rounded concretion of size about $2 \mathrm{~mm}$ was chosen arbitrarily and then removed, dried in ambient air, divided into four parts of similar size and subjected to chemical analysis, observation with scanning microscope, semi-quantitative determination of $\mathrm{Ca}, \mathrm{Mg}, \mathrm{Na}, \mathrm{K}, \mathrm{P}$ and $\mathrm{C}$ elements by EDX (energy dispersive X-ray), X-ray diffraction and FTIR (Fourier transform infra-red) spectroscopy carried out in the reflective mode.

\subsection{Electron Microscopy}

The samples were glued to a metallic support and observed using a Hitachi S 3400N scanning electron microscope and a Bruker EDX analyser. The samples were not covered with gold as its spectral line interferes with that of phosphorus and distorts the results of EDX analyses. Several randomly selected sites on each sample with areas of approximately $0.25 \mathrm{~mm}^{2}$ (hereafter referred to as a large area) and several areas inside each large site $0.25 \mu \mathrm{m}^{2}$ in size (hereafter referred to as small areas or point measurements) were subjected to EDX analysis.

\subsection{Chemical Analysis}

Samples of approximately $0.01 \mathrm{~g}$ (the smaller samples) and $0.1 \mathrm{~g}$ (the larger samples) from dry deposit were dissolved separately in $12 \mathrm{M} \mathrm{HCl}$ at ambient temperature for $24 \mathrm{~h}$, diluted to $10 \mathrm{ml}$ and filtered in order to remove undissolved particles of organic origin. The organic matter from the larger samples was dried and weighed. Each solution was then 100 times diluted with deionized water and used for the determination of calcium and magnesium or diluted with $0.6 \mathrm{M} \mathrm{H}_{2} \mathrm{SO}_{4}$ for phosphorus determination. Calcium forms a blue purple complex with Arzenazo III at neutral $\mathrm{pH}$ [8], magnesium forms a red complex with Calmagite in an alkaline solution [9] and phosphorus forms a green complex with malachite green molybdate under acidic conditions [10]. The intensity of solution discoloration was determined spectrophotometrically (Microplate Spectrophotometer PowerWave XS, Biotek Instruments, Inc., Winoosk, VT) at wave lengths of 650, 520 and $630 \mathrm{~nm}$ for $\mathrm{Ca}, \mathrm{Mg}$ and $\mathrm{P}$ respectively.

\subsection{X-Ray and Ftir Analysis}

A small piece from each concretion with a weight of about $2 \mathrm{mg}$ was pulverized and used for X-ray diffraction and then for FTIR reflective analysis. The X-ray spectra were obtained using XRD Diffractometer (BrukerSiemens D5000, Bruker AX GmbH Karlsruhe, Germany) and the FTIR spectra using a Bruker IFS66 infrared spectroscope (Bruker AXS GmbH Karlsruhe, Germany).

\section{RESULTS}

\subsection{Accuracy of the EDX Analyses}

The accuracy of the calcific concretions chemical composition determinations with EDX was assessed for 6 different samples. A small area of approximately $0.25 \mu \mathrm{m}^{2}$ in size was arbitrarily chosen from each of four samples and analysed and a large area of about $1 \mathrm{~mm}^{2}$ was selected on each of two samples. 12 successive measurements were carried out in each case. The arithmetical mean, standard deviation and median were determined for the $\mathrm{Ca} / \mathrm{P}$ and $\mathrm{Ca} / \mathrm{Mg}$ molar ratios in each series of measurements. The results are shown in Table 1.

As can be seen, the magnitude of the standard deviations are on average about 9 and $17 \%$ of the mean values for the $\mathrm{Ca} / \mathrm{P}$ and $\mathrm{Ca} / \mathrm{Mg}$ molar ratios determined with EDX respectively. The close coincidence of the arithmetic mean and median values indicates that in each series the distribution of individual measurements is nearly symmetrical.

\subsection{Fine Structure of the Deposits}

All studied calcifications of natural human aortic heart valve of approximately $2 \mathrm{~mm}$ in diameter were found to have uneven compact surfaces, see Figure 1(a). The interior of each calcification predominantly consists of blocks of structureless aspidinic matter, see Figure 1(b). Organic material including fibres was also observed. In fact, not a single site was found without organic matter, but its quantity varied significantly. The interiors of all of the studied deposits are highly inhomogeneous with-

Table 1. Accuracy of the EDX analyses.

\begin{tabular}{cccccccc}
\hline & & 1 & 2 & 3 & 4 & $5 *$ & $6 *$ \\
\hline $\mathrm{Ca} / \mathrm{P}$ & Mean & 1.342 & 1.525 & 1.361 & 1.476 & 1.315 & 1.792 \\
& $\sigma$ & 0.092 & 0.103 & 0.167 & 0.075 & 0.149 & 0.279 \\
& Median & 1.33 & 1.505 & 1.405 & 1.484 & 1.27 & 1.78 \\
$\mathrm{Ca} / \mathrm{Mg}$ & Mean & 5.13 & 31.12 & 7.96 & 9.33 & 8.26 & 27.44 \\
& $\sigma$ & 0.96 & 4.62 & 1.17 & 1.10 & 1.13 & 8.03 \\
& Median & 5.06 & 31.5 & 8.09 & 9.08 & 8.26 & 28.03 \\
\hline
\end{tabular}

* large area analyzed. 


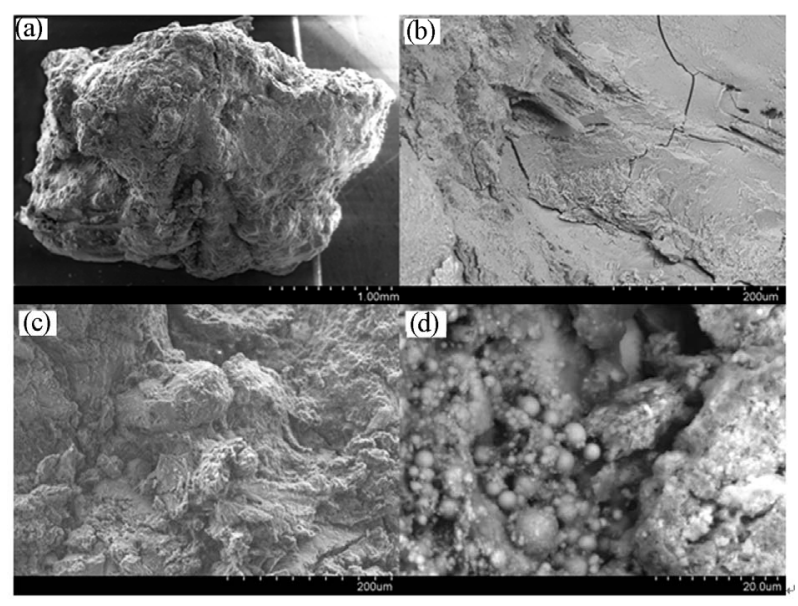

Figure 1. Internal structure of the calcific deposits. (a) surface of a deposit, (b) structureless aspidinic layer, (c)inhomogeneous interior, (d) small spheres in the cavity.

out a sign of any morphological order, see Figure 1(c). Small spheres situated in cavities of deposits were infrequently observed, see Figure 1(d).

\subsection{Chemical Composition of the Deposits}

The chemical composition of the deposits was determined using EDX and expressed as molar percentage of the constituting elements, specifically $\mathrm{Ca}, \mathrm{Mg}, \mathrm{Na}, \mathrm{K}, \mathrm{P}$ and $\mathrm{C}$. These data were converted into molar ratios $\mathrm{Ca} / \mathrm{P}$, $\mathrm{Ca} / \mathrm{Mg}, \mathrm{Ca} / \mathrm{C}$ and $\mathrm{Ca} /(\mathrm{K}+\mathrm{Na})$. Potassium was always present whereas sodium was missing in 11 out of the 87 data sets. Silicon, chlorine and sulphur were not detected by EDX in any of the studied deposits.

87 sets of data were obtained from the 15 samples. In 5 cases, specifically samples 6 through 10, two different deposits were removed from the same aortic valve and analyzed separately (the second denoted by an asterisk, e.g. $6 *)$. 15 sets containing over 20 molar\% of carbon (obviously organic matter adhering to the analyzed site surface) were excluded from further processing since a high content of carbon significantly distorts the determination of other elements.

The chemical composition of 15 studied calcifications determined by EDX analysis of areas of $0.25 \mathrm{~mm}^{2}$ and $0.25 \mu \mathrm{m}^{2}$ in size are summarized in Table 2 . Given values are the arithmetic means of all the data acquired for each sample.

The calculated molar ratio $\mathrm{Ca} / \mathrm{P}$ given in Table $\mathbf{1}$ varies in rather wide limits, specifically between 1.29 and 2.55 with the overall arithmetic mean (all individual values were taken into account) of $1.69 \pm 0.21$. There is substantial variation of the $\mathrm{Ca} / \mathrm{P}$ ratio not only between the large scanned areas of the same sample but also among point measurements within the same large area.

Magnesium was found to be present in approximately
$70 \%$ of the sites; sites with and without magnesium was detected on the same deposit and even within the same large area. When present, magnesium is a minor component amounting typically to around $5 \%$ of the calcium content (from 0.7 to $10 \mathrm{~mol} \%$ ). The molar ratio $\mathrm{Ca} / \mathrm{Mg}$ varies in extremely wide limits, from 16 to about 100 and exceptionally to 200, even within the same sample. The overall mean of the $\mathrm{Ca} / \mathrm{Mg}$ molar ratio is $23.6 \pm$ 11.5.

In contrast to magnesium, alkali metals were found to be always present in all of the studied aortic deposits. Sodium is absent from $15 \%$ of the measurements and sodium is always accompanied by potassium. The alkali metals are present at levels approximately $10 \mathrm{~mol} \%$ (the overall mean is $9.1 \pm 3.3$ ) of that of the main constituent calcium.

EDX is least reliable for carbon of the measured elements due to the proximity of its peak to the first peak of calcium. Carbon was detected at every investigated site, for both large and small areas. Low carbon content (with several exceptions that were excluded from further processing) indicates that it is present predominantly as inorganic carbon bound as carbonate in the apatitic phase. The $\mathrm{Ca} / \mathrm{C}$ molar ratio varies in the range 5-100, with an overall mean of $33.8 \pm 17.7$.

The compositions of 15 calcific deposits were determined by chemical (wet) analysis and are given in Table 3. The first and second values in each column represent are the results for the smaller and larger samples, respectively; wt.\% is the weight percentage of an organic matter in the larger sample.

\subsection{Structure of the Deposits}

The IR spectra of the 10 samples from different individuals are basically identical, see Figure 2. The spectra contain a broad, mostly featureless, absorbance band between 900 and $1200 \mathrm{~cm}^{-1}$ with an indistinct peak at $960 \mathrm{~cm}^{-1}$ and a high frequency shoulder typical of poorly crystalline hydroxyapatite [11]. The weak absorbance bands at $871 \mathrm{~cm}^{-1}$ and the very week bands at 1430 and $1455 \mathrm{~cm}^{-1}$ signify the presence of carbonate [11,12]. No band was detected at $864 \mathrm{~cm}^{-1}$ which if present would indicate the substitution of carbonates for the hydroxyl groups [13]. The broad band from 3700 to $2800 \mathrm{~cm}^{-1}$ and the weak band at $1645 \mathrm{~cm}^{-1}$ can be ascribed to structural water in the molecular form [5]. Based on the FTIR spectra all 10 studied deposits are composed of poorly crystalline carbonated hydroxyapatite.

The X-ray diffraction spectra of the investigated calcific deposits contain all the peaks characteristic of stoichiometric HAP, see Figure 3, and can be divided into a group with distinct merging of the 211 and 112 peaks, which is assumed to indicate the substitution of 
Table 2. Composition of 15 calcifications determined by EDX.

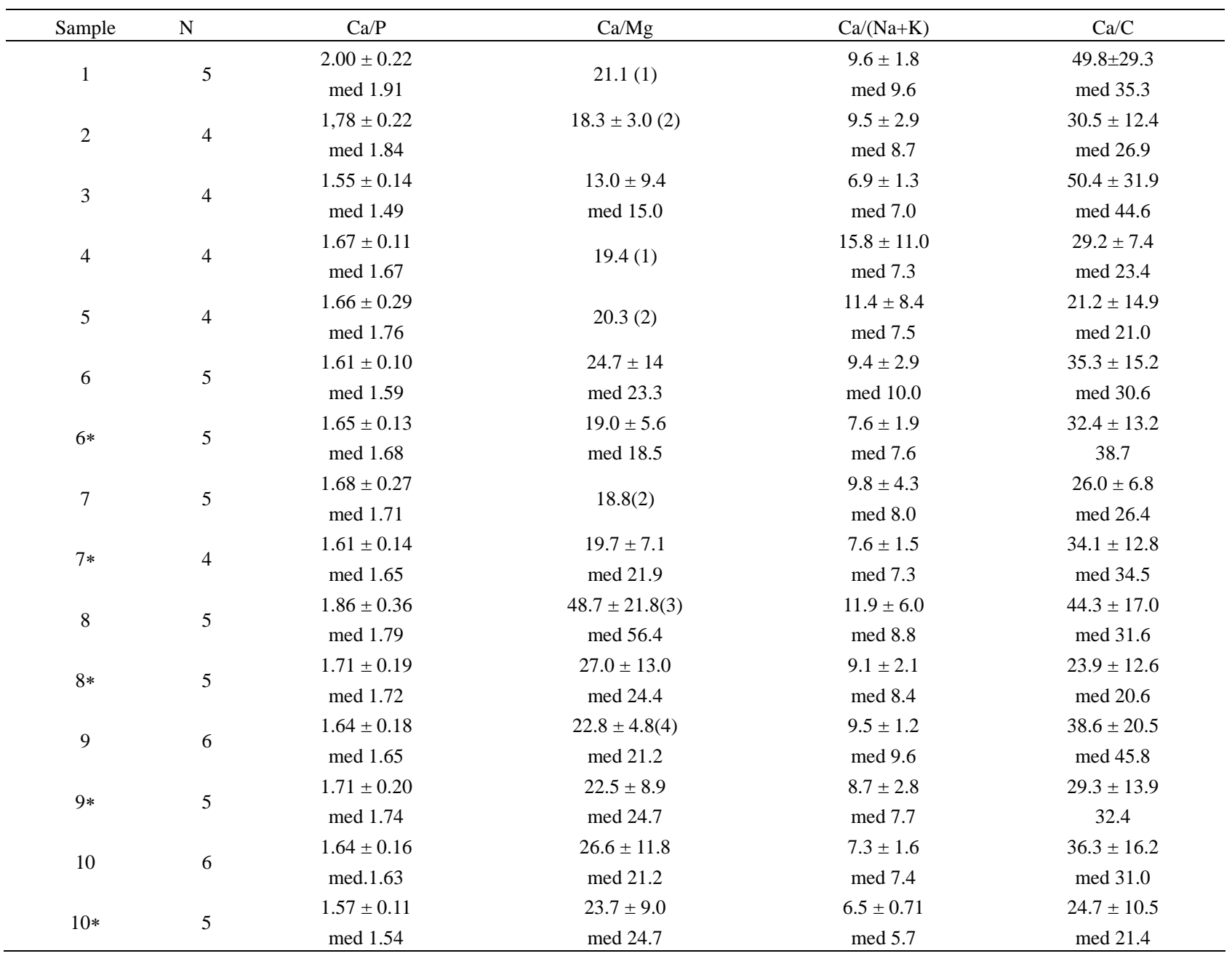

med - median; $\mathrm{N}$ - number of measurements; number in parentheses - number of determinations if different from $\mathrm{N} ; *-2^{\text {nd }}$ deposit from the same individual.

phosphate with carbonate [12], and a group for which

Table 3. Composition of 15 calcifications expressed as molar ratios determined by chemical analysis.

\begin{tabular}{cccccc}
\hline Sample & 1 & 2 & 3 & 4 & 5 \\
\hline $\mathrm{Ca} / \mathrm{P}$ & $1.25 ; 1.40$ & $1.79 ; 2.11$ & $1.45 ; 1.59$ & $1.61 ; 1.68$ & $1.58 ; 1.82$ \\
& $\varnothing 1.32$ & $\varnothing 1.95$ & $\varnothing 1.52$ & $\varnothing 1.64$ & $\varnothing 1.70$ \\
$\mathrm{Ca} / \mathrm{Mg}$ & $35 ; 18.2$ & & $26 ; 6.7$ & $30 ; 6.9$ & $37 ; 6.5$ \\
& $\varnothing 26.6$ & $; 11.4$ & $\varnothing 16.3$ & $\varnothing 18.4$ & $\varnothing 21.7$ \\
wt.\% & 15.5 & 13.8 & 18.1 & 11.5 & 17.2 \\
$\mathrm{Sample}$ & 6 & 7 & 8 & 9 & 10 \\
$\mathrm{Ca} / \mathrm{P}$ & $1.62 ; 1.83$ & $1.60 ; 1.57$ & $1.52 ; 1.82$ & $1.55 ; 1.49$ & $1.48 ; 1.67$ \\
& $\varnothing 1.72$ & $\varnothing 1.58$ & $\varnothing 1.67$ & $\varnothing 1.52$ & $\varnothing 1.57$ \\
$\mathrm{Ca} / \mathrm{P} *$ & 2.05 & 1.64 & 1.74 & 1.67 & 1.62 \\
$\mathrm{Ca} / \mathrm{Mg}$ & $35 ; 18.2$ & $26 ; 10.6$ & $30 ; 9.5$ & $28 ; 17.5$ & $27 ; 26.9$ \\
& $\varnothing 26.6$ & $\varnothing 18.3$ & $\varnothing 19.7$ & $\varnothing 22.7$ & $\varnothing 27$ \\
$\mathrm{Ca} / \mathrm{Mg} *$ & 10.4 & 6.8 & 12.6 & 6.9 & 18.9 \\
wt.\% & 18.9 & 9.0 & 16.4 & 23.3 & 15.0 \\
\hline
\end{tabular}

$*-2^{\text {nd }}$ deposit (a smaller sample) from the same individual this phenomenon is not observed. Samples 2, 4, 5, 7 and 10 belong to the former group. The comparison of the peaks and the background intensities according to [5] indicates that a significant fraction of amorphous phos-

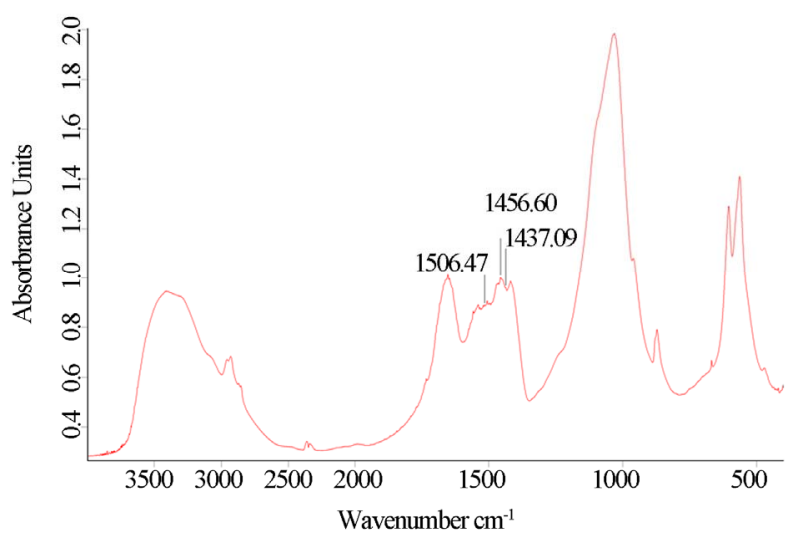

Figure 2. FTIR spectra of the calcific deposits.

Openly accessible at http://www.scirp.org/journal/JBPC/ 


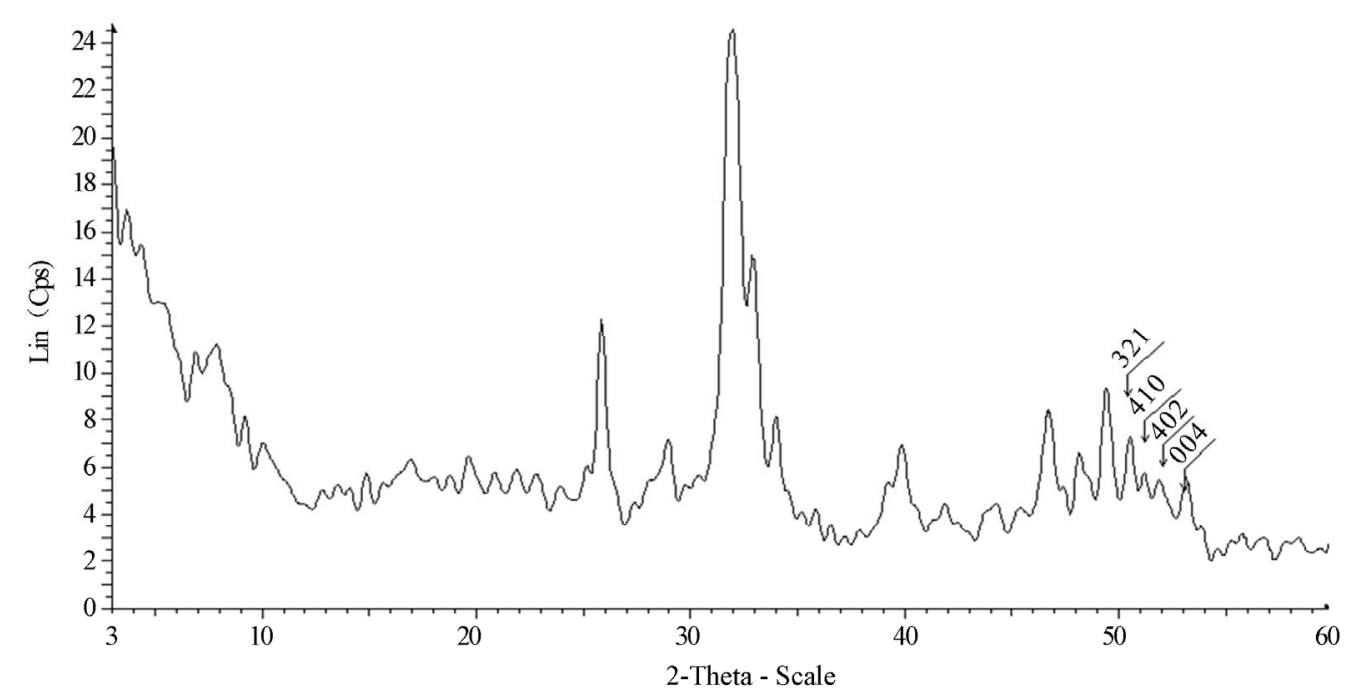

Figure 3. X-ray diffraction spectrum of sample No. 5.

phate is present in all studied samples.

\section{DISSCUSION}

The 15 studied natural human aortic calcific deposits consist of amorphous and poorly crystalline carbonated hydroxyapatite containing molecular water in which carbonate is substituted for phosphate and not hydroxyl groups as shown unambiguously by the X-ray and FTIR spectra. All deposits also contain between 9 and 23 wt.\% of organic matter.

The chemical composition of the calcifications varies widely not only among individual samples but also within the same deposit; even the composition of not too distant small areas (point composition) are dissimilar. Different deposits from the same individual do not have identical composition, but the deviations are not as profound as the variations among different individuals.

The composition of our deposits differs from that reported elsewhere [5,7] namely in the levels of potassium, magnesium and silicon. Our deposits contained nonnegligible amount of potassium and none silicon in contrast to virtually none potassium and about $3 \mathrm{~mol} \%$ of silicon or the "substantial incorporation of Si" [4,5].

When expressed in terms of the $\mathrm{Ca} / \mathrm{P}$ molar ratios of the smaller and larger samples, the chemical compositions of the same deposit are reasonably close. The $\mathrm{Ca} / \mathrm{P}$ ratio as determined by wet chemistry was found to vary between 1.25 and 2.11 with an overall mean of $1.61 \pm$ 0.19 . The $\mathrm{Ca} / \mathrm{P}$ molar ratio determined by EDX varied between 1.29 and 2.25 with an overall mean of $1.71 \pm$ 0.14 . Both values are below the average $1.83 \pm 0.03$ (spread 1.62-2.13) and $1.91 \pm 0.02$ (spread 1.87-1.93) reported for natural aortic deposits in [3] and [5] respec- tively, but are close to the value of 1.676 reported in [4]. The determined $\mathrm{Ca} / \mathrm{P}$ ratio corresponds to that of hydroxyapatite (1.67) which has also been found in mature arteriosclerotic plaque [1].

The $\mathrm{Ca} / \mathrm{P}$ ratios determined by EDX and wet chemistry are in good agreement with the exception of those of sample 1. Taking into account the accuracy of the chemical composition determination and the fact that the median is less influenced by a remote value than the arithmetical mean and is thus a better quantity for comparison, it seems that two different groups of deposits can be distinguished based on the $\mathrm{Ca} / \mathrm{P}$ ratio: 1) A group with high $\mathrm{Ca} / \mathrm{P}$ ratio-specifically samples $1,2,5$ and 8 and 2) A group with low $\mathrm{Ca} / \mathrm{P}$ ratio, namely samples 3,9 and 10. The remaining three samples 4, 6 and 7 exhibit composition that due to the uncertainty in the data cannot be unequivocally assigned to the abovementioned groups or identified as a third group with an intermediate composition. The other ratios, i.e. $\mathrm{Ca} / \mathrm{Mg}, \mathrm{Ca} /(\mathrm{Na}+\mathrm{K})$ and $\mathrm{Ca} / \mathrm{C}$, vary within the same limits in both groups. It should be stressed that the same classification transpires from both EDX and wet chemistry with the exception of sample 1 for which the difference between the analytical results is considerable.

The average $\mathrm{Ca} / \mathrm{P}$ ratios of the three distinct groups are 1.82, 1.66 and 1.59 using the arithmetic mean of medians or 1.82, 1.65 and 1.61 using EDX means and $1.80,1.65$ and 1.54 using wet analysis means. Thus it seems that the deposits belonging to the group with the high $\mathrm{Ca} / \mathrm{P}$ ratio consist of carbonated hydroxyapatite (theoretical $\mathrm{Ca} / \mathrm{P}>1.67$ ) whereas in deposits of the group with the low $\mathrm{Ca} / \mathrm{P}$ ratio amorphous calcium phosphate (theoretical $\mathrm{Ca} / \mathrm{P}=1.5$ ) prevails.

The $\mathrm{Ca} / \mathrm{Mg}$ molar ratio determined by wet chemistry 
seems to be less reliable than the $\mathrm{Ca} / \mathrm{P}$ ratio considering the significant differences between the smaller and larger samples shown in Table 3. The overall arithmetic mean is $21.4 \pm 10.4$. The $\mathrm{Ca} / \mathrm{Mg}$ ratio determined by EDX varies between 11.4 and 65.7 with an overall arithmetic mean $23.4 \pm 9.6$ which is, however, in a good agreement with the wet chemistry results. The amount of magnesium in our deposits is considerably higher than found in [5] which reported a value for the $\mathrm{Ca} / \mathrm{Mg}$ ratio of approximately 120 .

These results for the $\mathrm{Ca} / \mathrm{Mg}$ molar ratio indicate that magnesium is a minor component, if present at all, of the studied deposits; the magnesium content is on average only $5 \%$ of that of the major component, calcium. The content of magnesium varies not only among individual deposits but also among discrete parts of the same observed large area; some sites in a large area can contain magnesium even though the others do not.

Wet chemistry provides the composition averaged over a relatively large part of a deposit and so it reflects the total composition of the entire deposit rather than the variation of the composition within a deposit. EDX is the only currently available method for determining the chemical composition of selected small areas of deposits. However the accuracy of this method is rather limited, as can be seen in Table 1, and thus provides only rough insight into the inhomogeneities of deposit composition.

The data in Table 2 and specifically the comparison of the standard deviations and medians show the wide variations in the composition of the solid phase on the deposits. The data spread is narrower in the case of the large area measurements than in the case of the small area measurements. However, the average values of the $\mathrm{Ca} / \mathrm{P}$ and $\mathrm{Ca} / \mathrm{Mg}$ ratios determined for the small and large scanned areas of the same sample are reasonably close. The substantial difference between point composition of the phosphatic phase, particularly for deposits 1 , 2, 5, 7, 8, 9 and 10 and the large fluctuations of the magnesium concentration in nearly all samples are significant even when the uncertainties of $\pm 9 \%$ and $\pm 17 \%$ (the estimated magnitudes of standard deviation expressed as percentages of the mean) in the $\mathrm{Ca} / \mathrm{P}$ and $\mathrm{Ca} / \mathrm{Mg}$ ratios respectively are considered.

With only one exception, all the studied sites contained potassium, more frequently in combination with sodium, in proportions around $10 \mathrm{~mol} \%$ of the major component calcium. Potassium is in the minority if both elements are present. Potassium is a minor component of plasma, $4.5 \mathrm{mmol} / \mathrm{L}$ of potassium compared to 140 $\mathrm{mmol} / \mathrm{L}$ of sodium. The presence of potassium in the deposits is not an artefact created during the storage of the valves in formaldehyde solution containing also potassium because 1) The surfaces of the deposits are compact and thus resistant to penetration of solution into their interiors during storage, 2) The sites analyzed with EDX were situated inside each deposit, 3) The amount of potassium varies significantly between individual points situated close to each other and 4) The $\mathrm{Ca} /(\mathrm{Na}+\mathrm{K})$ ratio is fairly similar for different deposits and even throughout each deposit. Neither chlorine nor sulphur was detected in deposits which indicates that the alkali metals are not present in the form of chlorides or sulphates, so these elements are likely be incorporated in the HAP lattice replacing calcium.

EDX is least reliable for quantitative determination of carbon because carbon is a light element and also produces only one peak that is close to one of the two peaks of calcium. No site was without carbon. The average $\mathrm{Ca} / \mathrm{C}$ molar ratio was found to be around 30 (with several exceptions), i.e. the amount of carbon present is around 3 mol\% (a similar content of carbon was reported in [5]) which indicates that the carbon present is predominantly "inorganic" and therefore bound in the structure of phosphate. However, a substantial amount of organic matter which is not incorporated in the solid phase (between 9 and 23\%, see Table 3) indicates its important role in the formation of calcific deposits.

The composition of the solid phase, i.e. the Ca, P, K, $\mathrm{Na}, \mathrm{Mg}$ and $\mathrm{C}$ contents vary between the measured points in all studied deposits. Taking into account the randomness of the selection of analyzed sites we conclude that the composition of each deposit varies throughout its whole volume.

Based on the determined average molar ratios, $\mathrm{Ca} / \mathrm{P}=$ 1.71, $\mathrm{Ca} / \mathrm{Mg}=23, \mathrm{Ca} /(\mathrm{Na}+\mathrm{K})=9.3$ and $\mathrm{Ca} / \mathrm{C}=34$, the average total composition of the calcific deposits is generally $\mathrm{Ca}_{10-5 \mathrm{x}-\mathrm{y}} \mathrm{Mg}_{\mathrm{y}}(\mathrm{Na}, \mathrm{K})_{10 \mathrm{x}}\left(\mathrm{PO}_{4}\right)_{6-2 \mathrm{x}}\left(\mathrm{CO}_{3}\right)_{3 \mathrm{x}}(\mathrm{OH})_{2}$ where in our case $\mathrm{x}=0.1$ and $\mathrm{y}=0.4 \mathrm{tj}$. $\mathrm{Ca}_{9.1} \mathrm{Mg}_{0.4}(\mathrm{Na}, \mathrm{K})\left(\mathrm{PO}_{4}\right)_{5.8}\left(\mathrm{CO}_{3}\right)_{0.3}(\mathrm{OH})_{2}$. The respective molar ratios calculated from this formula, $\mathrm{Ca} / \mathrm{P}=1.57$, $\mathrm{Ca} / \mathrm{Mg}=22.7, \mathrm{Ca} /(\mathrm{Na}+\mathrm{K})=9.1$ and $\mathrm{Ca} / \mathrm{C}=30.3$, correspond well to the experimentally determined values. This formula is close to the formula $\mathrm{Ca}_{8.66} \mathrm{Mg}_{0.22} \mathrm{Na}_{0.32} \mathrm{H}_{0.14}\left(\mathrm{PO}_{4}\right)_{5}\left(\mathrm{CO}_{3}\right)_{1.22}(\mathrm{OH}, \mathrm{F}, \mathrm{Cl})_{0.80}$ suggested in [14]. The actual composition of the solid phase at various sites deviates from the formula given above.

\section{SUMMARY}

The studied human aortic valve calcific deposits contain poorly crystalline solid phase and can be divided into two distinct groups, one consisting predominantly of carbonated hydroxyapatite with high $\mathrm{Ca} / \mathrm{P}$ molar ratio and the other of amorphous calcium phosphate with lower $\mathrm{Ca} / \mathrm{P}$ molar ratio. The non-uniform internal fine structure of these deposits, the occasional appearance of spherical particles and the variable spatial point compo- 
sition of the individual deposits indicate that their formation does not proceed under constant conditions.

\section{ACKNOWLEDGMENTS}

This work was supported by Fundació Barceló (Ref. 1458/2007) and project grant CTF 2010-18271 from the Ministerio de ciencia $e$ innovación del Gobierno de España. I.G. expresses her appreciation to the Conselleria d'Innovació i Energia del Govern de les Illes Balears (Spain) for a fellowship supporting her work. O.S. is grateful to the University of Balearic Islands for grant which made this cooperation possible.

\section{REFERENCES}

[1] Tomazic, B.B., Brown, W.E. and Schoen, F.J. (1994) Physicochemical properties of calcific deposits isolated from porcine bioprosthetic heart valves removed from patients following 2-13 years function. Journal of Biomedical Materials Research Part A, 28(1), 35-47. doi:10.1002/jbm.820280106

[2] Tomazic, B.B., Edwards, W.D. and Schoen, F.J. (1995) Physicochemical characterization of natural and bioprosthetic heart valve calcific deposits: implications for prevention. The Annals of Thoracic Surgery, 60(Suppl. 2), S322-S327. doi:10.1016/0003-4975(95)00205-Y

[3] Mikroulis, D., Mavrilas, D., Kapolos, J., Koutsoukos P.G. and Lolas, C. (2002) Physicochemical and microscopical study of calcific deposits from natural and bioprosthetic heart valves. Comparison and implications for mineralization mechanism. Journal of Materials Science: Materials in Medicine, 13(9), 885-889.

doi:10.1023/A:1016556514203

[4] Delonge, C., Lawford, P.V., Habesch, S.M. and Carolan, V.A. (2007) Characterization of the calcification of cardiac valve bioprostheses by environmental scanning electron microscopy and vibrational spectroscopy. Journal of Microscopy, 228(1), 62-77. doi:10.1111/j.1365-2818.2007.01824.x

[5] Gilinskaya, L.G., Grigorieva, T.N., Okuneva, G.N. and Vlasov, Yu.A. (2003) Investigation of phatogenic mineralization on human heart valves. I. Chemical and phase composition. Journal of Structural Chemistry, 44(4),
622-631.

doi:10.1023/B:JORY.0000017938.42883.9f

[6] Gilinskaya, L.G., Okuneva, G.N. and Vlasov, Yu.A. (2003) Investigation of pathogenic mineralization on human heart valves. II. ESR spectroscopy. Journal of Structural Chemistry, 44(5), 813-820. doi:10.1023/B:JORY.0000029819.16581.8a

[7] Gilinskaya, L.G., Rudina, N.A., Okuneva, G.N. and Vlasov, Yu.A. (2003) Pathogenic mineralization on human heart valves. III. Electron microscopy. Journal of Structural Chemistry, 44(6), 1038-1045. doi:10.1023/B:JORY.0000034811.28903.9b

[8] Michaylova, V. and Ilkova, P. (1971) Photometric determination of micro amounts of calcium with arsenazo III. Analytica Chimica Acta, 53(1), 194-198. doi:10.1016/S0003-2670(01)80088-X

[9] Chauman, U.P.S. and Ray Sarkar, B.C. (1969) Use of calmagite for the determination of traces of magnesium in biological materials. Analytical Biochemistry, 13(1), 70-80. doi:10.1016/0003-2697(69)90105-5

[10] Martin, M., Celi, L. and Barberis, E. (1999) Determination of low concentrations of organic phosphorus in soil solution. Communications in soil science and plant analysis, 30(13-14), 1909-1917. doi:10.1080/00103629909370341

[11] Pleshko, N., Boskey, A. and Mendelsohn, R. (1991) Novel infrared spectroscopic method for the determination of crystallinity of hydroxyapatite minerals. Biophysical Journal, 60(4), 786-793. doi:10.1016/S0006-3495(91)82113-0

[12] Kapolos, J. and Koutsoukos, P.G. (1999) Formation of calcium phosphate in aqueous solutions in the presence of carbonate ions. Langmuir, 15(19), 6557-6562. doi:10.1021/la981285k

[13] Ito, A., Maekawa, K., Tsutsumi, S., Ikazaki, F. and Tateishi, T. (1997) Solubility product of OH-carbonated hydroxyapatite. Journal of Biomedical Materials Research Part A, 36(4), 522-528. doi:10.1002/(SICI)1097-4636(19970915)36:4<522::AID -JBM10>3.0.CO;2-C

[14] Tomazic, B.B. (2001) Physicochemical principles of cardiovascular calcification. Clinical Research in Cardiology, 90(Suppl. 2), 1168-1180. 